
D:\Nsurg \Vol. 24, No. 3, Jul. - Sep., 2020\Nsurg-8.Doc
(A)
P. $216-224$
II

ORIGINAL ARTICLE

\title{
Comparison of Stereotactic Subthalamotomy and Ventralis Intermedius (VIM) Thalamotomy in Relieving Parkinsonian Tremor
}

\author{
SOMRAJ LAMICHHANE, KHALID MAHMOOD \\ Department of Neurosurgery, Punjab Institute of Neurosciences (PINS), Lahore General Hospital, \\ Lahore - Pakistan
}

DOI: $10.36552 /$ pjns.v24i3.464

\begin{abstract}
Background/Objectives: Parkinson's disease is a neurodegenerative disease with cardinal features of tremor, rigidity, postural instability and bradykinesia. Surgery is indicated for the patients not responding to medical management or who develop motor fluctuations and dyskinesia following prolonged levodopa therapy. Stereotactic Subthalamotomy and VIM (Ventralis Intermedius) Thalamotomy is cheap, safe and effective surgical options for the treatment of Parkinsonian tremor. The objective of the study was to compare Stereotactic Subthalamotomy with Ventralis Intermedius (VIM) Thalamotomy, in terms of improvement in Unified Parkinson's Disease Rating Scale (UPDRS), for the treatment of Parkinsonian tremor.
\end{abstract}

Material and Methods: This is a randomized control trial (RCT) and 38 tremor predominant Parkinsonian patients were enrolled in the study. Half of the patients underwent Stereotactic Subthalamotomy and another half underwent VIM Thalamotomy. Patients were assessed pre-operatively, immediately post-operatively and followed up at three weeks, six weeks and three months by using UPDRS scores.

Results: The mean age of patients was 59.58 years and they were predominantly male. Post-operative UPDRS score was improved significantly in both STN and VIM groups. However, the improvement was significantly higher in STN lesioning compared to VIM lesioning. On the other hand, the improvement in tremor component score of UPDRS was comparable in the both groups. Moreover, post-operative complications were higher following Subthalamotomy (21.05\%) which included dyskinesia, dysphasia, transient weakness and hematoma formation.

Conclusion: Both Stereotactic Subthalamotomy and VIM Thalamotomy are equally effective in relieving Parkinsonian tremor with a lower complication rate following VIM Thalamotomy.

Keywords: Parkinson's disease, Subthalamotomy, VIM Thalamotomy, Unified Parkinson's disease Rating Score. Abbreviations: VIM: Ventralis Intermedius. RCT: Randomized Control Trial. PD: Parkinson 's disease. UPDRS: Unified Parkinson's disease Rating Scale. DBS: Deep Brain Stimulation. STN: Subthalamic Nucleus.

\section{INTRODUCTION}

The study was aimed to compare the Stereotactic Subthalamotomy with Ventralis Intermedius (VIM) Thalamotomy, in terms of improvement in Unified Parkinson's Disease Rating Scale (UPDRS), for the treatment of Parkinsonian tremor.

Parkinson's disease (PD) is a progressive neurodegenerative disease with an incidence of 4.5 to 21 per 100,000 populations per year, which is only second to Alzheimer's disease. ${ }^{1}$ The average age of onset is 60 years with male predominance. ${ }^{2}$ Two major neuropathological findings in this disease are loss of pigmented dopaminergic neurons in substantia nigra and the presence of Lewy bodies and Lewy neuritis. 3,4 
Clinical diagnosis is made on the basis of four characteristic features: resting tremor, rigidity, postural instability and bradykinesia. ${ }^{5}$

Levodopa along with carbidopa, remains the standard medical treatment of motor symptoms of the disease. However, some patients present with motor fluctuations and dyskinesia with its long term use. ${ }^{6}$ Thus, surgical treatment is reserved for patients with either decrease response to medical treatment or development of drug related complications.

Deep Brain Stimulation (DBS) of VIM (Ventralis Intermedius) nucleus or STN (Subthalamic nucleus) is a surgery of choice for Parkinsonian tremor but it is an expensive procedure. Alternate cheap, safe and effective surgical options are Stereotactic Subthalamotomy and VIM Thalamotomy. Today, the provision of magnetic resonance based images along with the development of SurgiPlan workstation with inbuilt digital brain atlas; the localization of target has become more precise. Furthermore, safe trajectory to the target can be defined avoiding sulci, ventricles and internal capsule reducing surgical morbidity. Final level of accuracy lies in functional mapping using pre-operative macro-electrode stimulation in awake before making permanent lesion using radiofrequency lesion generator. ${ }^{7}$

\section{MATERIAL AND METHODS}

\section{Study Design and Setting}

It was the randomized control trial (RCT) conducted in the Department of Neurosurgery (Unit-II), Lahore General Hospital (LGH), Lahore, Pakistan from March 2015 to February 2017 after clearance from the ethical committee. Non probability, purposive sampling technique was used. Thirty eight patients were enrolled in the study. Allocation of a particular procedure was done by random method. Half of the patients were operated via. Subthalamotomy and the other half were operated via. VIM Thalamotomy. Informed consents were taken from all patients fulfilling the inclusion criteria after explaining details of the procedure, outcome, and risks.

\section{Inclusion Criteria}

Patients included in the study were medically refractory Parkinsonian patients getting maximum doses of carbidopa (200 mg/day) and Levodopa (800 $\mathrm{mg}$ /day) for at least 6 months and those who developed drug induced dyskinesia.

\section{Exclusion Criteria}

Patients with tremors due to stroke/infarction, head injury or demyelination; lesions in basal ganglia; those having malignant diseases, bleeding diathesis and cognitive decline were excluded from the study.

\section{Data Collection and Clinical Management}

Detail history and neurological assessment of enrolled patients were carried out and preoperative UPDRS was recorded. Pre-operatively MRI brain (non-contrast) was done in all patients to rule out any structural abnormality. All the Parkinsonian drugs were stopped one day before surgery.

\section{Procedure}

After application of stereotactic Leksell $\mathrm{G}$ frame under local anesthesia, MRI Brain with contrast was done and the image was transferred to SurgiPlan workstation. Then the target was calculated for Subthalamic nucleus (STN) and VIM nucleus using Laitinen formula. This acquired target on MRI was confirmed by superimposing on Shelton Bran digital brain atlas. Once the desired target was confirmed, the trajectory was determined with SurgiPlan avoiding sulci, ventricles, internal capsule and blood vessels.

The Leksell frame was fixed to the OT table adjusting $\mathrm{X}, \mathrm{Y}, \mathrm{Z}$, arc and rings according to the calculations. A $14 \mathrm{~mm}$ burr hole was made under local anesthesia. A stereotactic $2.1 \mathrm{~mm}$ microelectrode was then inserted while the frame was adjusted in such a way that tips of electrode were $-4 \mathrm{~mm}$ above the target (zero). The electrode was connected through leads to the Cosman lesion generator with stimulation parameters set at a frequency of $130 \mathrm{~Hz}$, voltage of 1.5 Volts and pulse width of 0.2 milliseconds. The electrode was gradually advanced at $2 \mathrm{~mm}$ interval till patient's symptoms disappeared. During stimulation patients were evaluated for the disappearance of tremors and side effects of stimulation like contralateral tetanic contractions of arms and legs, contralateral deviation of eyes, any paresthesias or visual hallucinations. Once the target was physiologically confirmed, a permanent lesion was made by setting temperature at $50^{\circ} \mathrm{C}$ for one minute, then on $70^{\circ} \mathrm{C}$ and finally on $90^{\circ} \mathrm{C}$ for one minute. 
Comparison of Stereotactic Subthalamotomy and Ventralis Intermedius (VIM) Thalamotomy in Relieving

\section{Post-Operative Management}

Post-operatively, the patients were shifted to the recovery room and $\mathrm{CT}$ scan was obtained after 8 hours, to see any hematoma. The pre-op medications for Parkinsonism were restarted. Patients were evaluated in the next morning and UPDRS score along with any complications were recorded. An MRI scan with $2 \mathrm{~mm}$ cuts of $\mathrm{T} 1 \mathrm{~W}$ and $\mathrm{T} 2 \mathrm{~W}$ images was obtained to confirm the placement of lesion. Patients were then discharged on medications with doses readjusted in consultation with neurologist. Follow up was done with UPDRS score at 3 weeks, 6 weeks and 3 months.

\section{Data Analysis}

Statistical analysis was done using Statistical Package for Social Sciences (SPSS) version 22. The qualitative data like demographics were documented as percentage and frequency distribution tables and compared using chi-square test. The quantitative data like age were presented in Mean \pm Standard Deviation.

After fulfilling the parametric test assumptions, paired sample t-test was used to compare differences before and after treatment in the UPDRS score and independent sample student's t-test was applied to determine the significant differences between the UPDRS score of both groups. The $p$ value of $\leq 0.05$ was considered as significant.

\section{RESULTS}

Thirty eight patients were
Table 1: Distribution of Patient by Age in Both Study Groups.

\begin{tabular}{|c|l|c|c|c|c|c|}
\hline & Study Groups & Mean & $\begin{array}{c}\text { Standard } \\
\text { Deviation (S.D) }\end{array}$ & Minimum & Maximum & $\begin{array}{c}\text { P } \\
\text { value }\end{array}$ \\
\hline \multirow{2}{*}{$\begin{array}{c}\text { Age } \\
\text { (years) }\end{array}$} & STN (n=19) & 61.00 & 5.48 & 50 & 70 & \\
\cline { 2 - 7 } & VIM (n=19) & 58.16 & 5.44 & 45 & 67 & \multirow{2}{*}{0.118} \\
\cline { 2 - 6 } & Total $(\mathrm{n}=38)$ & 59.58 & 5.58 & 45 & 70 & \\
\hline
\end{tabular}

Table 2: Comparison of Presenting Complaints in Both Study Groups.

\begin{tabular}{|c|c|c|}
\hline \multirow{2}{*}{ Presenting Complaints } & \multicolumn{2}{|c|}{ Study Groups } \\
\hline & STN Group & VIM Group \\
\hline Bilateral tremor with mild rigidity and bradykinesia & $7(36.84 \%)$ & $6(31.58 \%)$ \\
\hline $\begin{array}{l}\text { Predominant right sided tremor with mild rigidity } \\
\pm \text { bradykinesia }\end{array}$ & $5(26.31 \%)$ & $7(36.84 \%)$ \\
\hline $\begin{array}{l}\text { Predominant left sided tremor with mild rigidity } \\
\pm \text { bradykinesia }\end{array}$ & $4(21.05 \%)$ & $4(21.05 \%)$ \\
\hline Unilateral tremor with bradykinesia & $3(15.78 \%)$ & $2(10.53 \%)$ \\
\hline Total & 19 & 19 \\
\hline
\end{tabular}

Table 3: Comparison of Duration of Disease and Treatment in Both Study Groups.

\begin{tabular}{|l|l|l|l|l|l|c|}
\hline & Study Groups & Mean & S.D & Minimum & Maximum & P value \\
\hline \multirow{4}{*}{$\begin{array}{l}\text { Duration of } \\
\text { Disease (Years) }\end{array}$} & STN (n=19) & 9.16 & 3.55 & 3.00 & 15.00 & \\
\cline { 2 - 6 } & VIM (n=19) & 8.89 & 3.70 & 3.00 & 15.00 & \multirow{2}{*}{0.824} \\
\cline { 2 - 6 } & Total (n=38) & 9.03 & 3.58 & 3.00 & 15.00 & \\
\hline \multirow{2}{*}{$\begin{array}{l}\text { Duration of } \\
\text { Treatment } \\
\text { (Years) }\end{array}$} & STN (n=19) & 7.26 & 3.87 & 2.00 & 15.00 & \multirow{2}{*}{0.970} \\
\cline { 2 - 6 } & VIM (n=19) & 7.32 & 4.62 & 2.00 & 15.00 & \\
\cline { 2 - 6 } & Total (n=38) & 7.29 & 4.20 & 2.00 & 15.00 & \\
\hline
\end{tabular}

Table 4: Comparison between Pre-operative and Post-operative UPDRS Score in Subthalamotomy (STN) Group.

\begin{tabular}{|l|l|l|l|}
\hline \multicolumn{1}{|l|}{} & Mean & SD & t-test (p value) \\
\hline Pre-operative & 19.32 & 1.797 & \\
\hline Paired Comparison & \multicolumn{2}{|l|}{} \\
\hline Pre-operative vs. Immediate post-operative & 7.95 & 1.224 & $33.92(<0.0001)$ \\
\hline Pre-operative vs. 3 weeks follow-up & 7.89 & 0.994 & $40.92(<0.0001)$ \\
\hline Pre-operative vs. 6 weeks follow up & 7.53 & 1.124 & $43.46(<0.0001)$ \\
\hline Pre-operative vs. 3 months follow-up & 7.47 & 1.073 & $41.00(<0.0001)$ \\
\hline $\begin{array}{l}\text { Immediate post-operative vs. } \\
\text { 3 months post-operative }\end{array}$ & 7.95 & 1.224 & \\
\hline
\end{tabular}


Table 5: Comparison between Pre-operative and Postoperative UPDRS Scores in VIM Thalamotomy Group.

\begin{tabular}{|l|l|l|l|}
\hline & Mean & SD & t-test (p value) \\
\hline Pre-operative & 18.58 & 1.610 & \multicolumn{2}{|l|}{} \\
\hline Paired Comparison & \multicolumn{2}{|l|}{} \\
\hline $\begin{array}{l}\text { Pre-operative vs. } \\
\text { Immediate post-operative }\end{array}$ & 9.0 & 1.106 & $\begin{array}{l}46.311 \\
(<0.0001)\end{array}$ \\
\hline $\begin{array}{l}\text { Pre-operative vs. } \\
3 \text { weeks follow-up }\end{array}$ & 8.84 & 1.214 & $45.47(<0.0001)$ \\
\hline $\begin{array}{l}\text { Pre-operative vs. } \\
6 \text { weeks follow up }\end{array}$ & 8.63 & 1.116 & $47.58(<0.0001)$ \\
\hline $\begin{array}{l}\text { Pre-operative vs. } \\
3 \text { months follow-up }\end{array}$ & 8.53 & 1.264 & $34.55(<0.0001)$ \\
\hline $\begin{array}{l}\text { Immediate post-operative vs. } \\
3 \text { months post-operative }\end{array}$ & $\begin{array}{l}9.0 \\
8.53\end{array}$ & $\begin{array}{l}1.106 \\
1.264\end{array}$ & $2.964(0.008)$ \\
\hline
\end{tabular}

included in our study, 19 each in VIM Thalamotomy and Subthalamotomy (STN) group.

\section{Gender Distribution:}

There were $14(73.68 \%)$ male and $5(26.32 \%)$ females in the STN group while $17(89.47 \%)$ male and 2 $(10.53 \%)$ females in VIM group, $p$-value $>0.05$.

\section{Distribution of Patient by Age:}

Overall mean age of the patients was $59.58 \pm 5.44$ years. The mean age in VIM and STN group was $61 \pm$ 5.48 and $58.16 \pm 5.44$ years, respectively (Table 1 ).

\section{Distribution of Patients According to Presenting Complaints:}

Majority of the patients presented with bilateral symptoms (tremor, rigidity and bradykinesia) in both the groups followed by predominantly right sided tremor, rigidity and bradykinesia. Presentation with only unilateral tremor was least common in both VIM Thalamotomy and Subthalamotomy groups (Table 2).

\section{Duration of Disease and Treatment:}

The mean duration of disease in STN group and VIM group was $9.16 \pm 3.55$ years and $8.89 \pm 3.70$ years respectively whereas, the mean duration of treatment in STN group was $7.26 \pm 3.87$ years and VIM group was $7.32 \pm 4.62$ years, with no statistical difference between means (Table 3).

Comparison between Pre-operative and Postoperative UPDRS Scores in Subthalamotomy Group:

The mean UPDRS score was significantly reduced in immediate post-operative period when compared to pre-operative score and the improvement was persistently sustained throughout the 3 weeks, 6 weeks and 3 months follow-up. Similarly, after 3 months of procedure the mean UPDRS score was improved significantly when compared to post-operative score with $\mathrm{p}<0.05$ (Table 4).

Comparison between Pre-operative and Postoperative UPDRS Scores in VIM Thalamotomy Group:

The mean UPDRS score was significantly reduced in immediate post-operative period when compared to pre-operative score and the improvement was persistently sustained throughout the 3 weeks, 6 weeks and 3 months follow-up. Similarly, after 3 months of procedure the mean UPDRS score was improved significantly when compared to post-operative score with $\mathrm{p}<0.05$ (Table 5).

\section{Comparison of UPDRS Scores between Subthalamotomy (STN) and VIM Thalamotomy Groups:}

The difference in mean pre-operative UPDRS score between STN $(19.32 \pm 1.80)$ and VIM $(18.58 \pm 1.6)$ was not statistically significant $(\mathrm{p}=0.191)$. After surgery, it was observed as $7.95 \pm 1.22$ in STN group and $9.0 \pm 1.11$ in VIM group. This shows statistically significant improvement in UPDRS score following Subthalamotomy compared to VIM Thalamotomy. It was observed that improvement in terms of UPDRS score was significantly more and sustained throughout 3 weeks, 6 weeks and 3 months follow-up in STN group as compared to VIM Thalamotomy group with $\mathrm{p}<0.05$ (Table 6).

\section{Comparison of Mean Tremor Component score} of UPDRS Before and After Surgery in Subthalamotomy (STN) Group:

The mean pre-operative tremor component score of UPDRS score was significantly reduced after 
Comparison of Stereotactic Subthalamotomy and Ventralis Intermedius (VIM) Thalamotomy in Relieving

Table 6: Comparison of UPDRS Score in Both Study Groups.

\begin{tabular}{|c|c|c|c|c|c|c|}
\hline UPDRS Score & Study Groups & Mean & S.D & Minimum & Maximum & t-test (p value) \\
\hline \multirow{3}{*}{ Pre-operative } & STN $(n=19)$ & 19.32 & 1.80 & 17 & 23 & \multirow{3}{*}{$1.33(0.191)$} \\
\hline & $\operatorname{VIM}(n=19)$ & 18.58 & 1.61 & 16 & 22 & \\
\hline & Total $(\mathrm{n}=38)$ & 18.95 & 1.72 & 16 & 23 & \\
\hline \multirow{2}{*}{ Post-operative } & $\operatorname{STN}(n=19)$ & 7.95 & 1.22 & 6 & 10 & \multirow{2}{*}{$-2.78(0.009)$} \\
\hline & $\operatorname{VIM}(n=19)$ & 9.00 & 1.11 & 7 & 11 & \\
\hline \multirow{2}{*}{3 weeks } & $\operatorname{STN}(n=19)$ & 7.89 & 0.99 & 6 & 10 & \multirow{2}{*}{$-2.63(0.012)$} \\
\hline & $\operatorname{VIM}(\mathrm{n}=19)$ & 8.84 & 1.21 & 7 & 11 & \\
\hline \multirow{2}{*}{6 weeks } & $\operatorname{STN}(n=19)$ & 7.53 & 1.12 & 6 & 10 & \multirow{2}{*}{$-3.04(0.004)$} \\
\hline & $\operatorname{VIM}(n=19)$ & 8.63 & 1.12 & 7 & 11 & \\
\hline \multirow{2}{*}{3 months } & $\operatorname{STN}(\mathrm{n}=19)$ & 7.47 & 1.07 & 6 & 9 & \multirow{2}{*}{$-2.76(0.009)$} \\
\hline & $\operatorname{VIM}(n=19)$ & 8.53 & 1.26 & 7 & 11 & \\
\hline
\end{tabular}

and 3 months with $\mathrm{p}<0.05$. Similarly, while comparing immediate post-operative score with 3 months follow up score, the improvement was statistically significant (table 7).

\section{Comparison of Mean Tremor Component Score of UPDRS before and After Surgery in VIM Thalamotomy Group:}

The mean pre-operative tremor component score of UPDRS score was significantly reduced after surgery and during subsequent follow up at 3 weeks, 6 weeks and 3 months with $\mathrm{p}<0.05$. Similarly, while comparing immediate post-operative score with 3 months follow up score, the improvement was statistically significant (table 8 ).

\section{Comparison of Tremor Component Score of UPDRS between Two Study Groups:}

The mean pre-operative tremor component of UPDRS score was 2.63 \pm 0.49 and $2.57 \pm 0.50$ in STN and VIM group respectively, the difference was not statistically significant $(\mathrm{p}=0.748)$. The mean tremor component was $0.78 \pm 0.71$ in
Table 7: Comparison of Mean Tremor Component Score of UPDRS before and After Surgery in Subthalamotomy (STN) Group.

\begin{tabular}{|c|c|c|c|}
\hline & $\begin{array}{l}\text { Tremor component of } \\
\text { UPDRS score (Mean) }\end{array}$ & SD & t-test (p value) \\
\hline Pre-operative & 2.63 & 0.50 & \\
\hline \multicolumn{4}{|l|}{ Paired Comparison } \\
\hline $\begin{array}{l}\text { Pre-operative vs. } \\
\text { Immediate post-operative }\end{array}$ & 0.79 & 0.71 & $8.93(<0.001)$ \\
\hline $\begin{array}{l}\text { Pre-operative vs. } \\
3 \text { weeks follow-up }\end{array}$ & 0.68 & 0.67 & $10.01(<0.001)$ \\
\hline $\begin{array}{l}\text { Pre-operative vs. } \\
6 \text { weeks follow up }\end{array}$ & 0.53 & 0.51 & $12.44(<0.001)$ \\
\hline $\begin{array}{l}\text { Pre-operative vs. } \\
3 \text { months follow-up }\end{array}$ & 0.53 & 0.51 & $12.44(<0.001)$ \\
\hline $\begin{array}{l}\text { Immediate post-operative vs. } \\
3 \text { months post-operative }\end{array}$ & $\begin{array}{l}0.79 \\
0.53\end{array}$ & $\begin{array}{l}0.71 \\
0.51\end{array}$ & $2.53(0.021)$ \\
\hline
\end{tabular}

Table 8: Comparison of Mean Tremor Component Score of UPDRS before and After Surgery in VIM Thalamotomy Group.

\begin{tabular}{|l|c|c|l|}
\hline & $\begin{array}{c}\text { Tremor component of } \\
\text { UPDRS score (Mean) }\end{array}$ & SD & \multicolumn{1}{|c|}{$\begin{array}{c}\text { t-test } \\
\text { (p value) }\end{array}$} \\
\hline Pre-operative & 2.58 & 0.51 & \multicolumn{2}{|l|}{} \\
\hline Paired Comparison & \multicolumn{3}{|l|}{} \\
\hline $\begin{array}{l}\text { Pre-operative vs. } \\
\text { Immediate post-operative }\end{array}$ & 0.74 & 0.65 & $\begin{array}{l}10.50 \\
(<0.001)\end{array}$ \\
\hline $\begin{array}{l}\text { Pre-operative vs. } \\
\text { 3 weeks follow-up }\end{array}$ & 0.74 & 0.45 & $\begin{array}{l}11.67 \\
(<0.001)\end{array}$ \\
\hline $\begin{array}{l}\text { Pre-operative vs. } \\
\text { 6 weeks follow up }\end{array}$ & 0.58 & 0.51 & $\begin{array}{l}11.69 \\
(<0.001)\end{array}$ \\
\hline $\begin{array}{l}\text { Pre-operative vs. } \\
\text { 3 months follow-up }\end{array}$ & 0.58 & 0.51 & $\begin{array}{l}11.69 \\
(<0.001)\end{array}$ \\
\hline $\begin{array}{l}\text { Immediate post-operative vs. } \\
\text { 3 months post-operative }\end{array}$ & 0.74 & 0.65 & \\
0.58 & 0.51 & $1.83(0.083)$ \\
\hline
\end{tabular}


STN group and $0.73 \pm 0.0 .65$ in VIM group during immediate post-operative period which was not significantly different. Similarly, difference in improvement in tremor scores between two groups during subsequent follow up at 3 weeks, 6 weeks and 3 months was also comparable statistically (Table 9).

Table 9: Comparison of Tremor Component of UPDRS Score in Both Study Groups.

\begin{tabular}{|c|c|c|c|c|}
\hline $\begin{array}{l}\text { Tremor Component } \\
\text { of UPDRS Score }\end{array}$ & Procedure & Mean & S.D & P value \\
\hline \multirow{2}{*}{ Pre-operative } & $\operatorname{STN}(\mathrm{n}=19)$ & 2.63 & 0.49 & \multirow{2}{*}{0.748} \\
\hline & $\operatorname{VIM}(\mathrm{n}=19)$ & 2.57 & 0.50 & \\
\hline \multirow{2}{*}{$\begin{array}{l}\text { Immediate post- } \\
\text { operative }\end{array}$} & $\operatorname{STN}(\mathrm{n}=19)$ & 0.78 & 0.71 & \multirow{2}{*}{0.814} \\
\hline & $\operatorname{VIM}(\mathrm{n}=19)$ & 0.73 & 0.65 & \\
\hline \multirow{2}{*}{3 weeks follow-up } & $\operatorname{STN}(n=19)$ & 0.68 & 0.67 & \multirow{2}{*}{0.778} \\
\hline & $\operatorname{VIM}(\mathrm{n}=19)$ & 0.73 & 0.45 & \\
\hline \multirow{2}{*}{6 weeks follow up } & $\operatorname{STN}(\mathrm{n}=19)$ & 0.52 & 0.51 & \multirow{2}{*}{0.752} \\
\hline & $\operatorname{VIM}(\mathrm{n}=19)$ & 0.57 & 0.50 & \\
\hline \multirow{2}{*}{3 months follow up } & $\operatorname{STN}(\mathrm{n}=19)$ & 0.52 & 0.52 & \multirow{2}{*}{0.753} \\
\hline & $\operatorname{VIM}(\mathrm{n}=19)$ & 0.57 & 0.50 & \\
\hline
\end{tabular}

\section{Post-operative Complications}

Overall, $10.52 \%$ and $21.05 \%$ complications occurred in VIM and STN groups, respectively $(\mathrm{p}<0.05)$. One patient in VIM group had surgical site infection that was treated with antibiotics. One patient in each group had transient weakness that improved within few weeks. Similarly, three more complications were encountered in STN group (dyskinesia, dysphasia and small intraparenchymal hematoma). Dyskinesia in contralateral upper limb was managed with readjustment of anti-Parkinsonian medications and disappeared completely at the end of 3 months. Similarly, expressive dysphasia was seen in one patient who showed gradual improvement during subsequent follow-up. Small intraparenchymal hematoma (volume $<10 \mathrm{ml}$ ) in one patient was managed conservatively (Table 10).
Table 10: Comparison of Complications in Both Study Groups.

\begin{tabular}{|l|l|c|}
\hline \multirow{2}{*}{ Complications } & \multicolumn{2}{|c|}{ Study Groups } \\
\cline { 2 - 3 } & VIM & STN \\
\hline Wound infection & $1(5.26 \%)$ & $0(0 \%)$ \\
\hline Transient weakness & $1(5.26 \%)$ & $1(5.26 \%)$ \\
\hline Dyskinesia & $0(0 \%)$ & $1(5.26 \%)$ \\
\hline Dysphasia & $0(0 \%)$ & $1(5.26 \%)$ \\
\hline Small hematoma & $0(0 \%)$ & $1(5.26 \%)$ \\
\hline
\end{tabular}

\section{DISCUSSION}

Parkinson's disease is a progressive neurodegenerative disease affecting middle age to elderly population. Onset of the disease is after sixth decade of life and less than $4 \%$ of the Parkinsonian patients are below 50 years of age. ${ }^{8}$ The mean age of presentation in our study is 59.58 years with range of $45-70$ years. Progression of the disease with age is attributed to progressive degeneration of dopaminergic neurons in substantia nigra. ${ }^{9}$ The disease is more common in men than women (gender ratio: $1.5: 1-2: 1)^{2,8}$ The male to female ratio in our study was $4.4: 1$. This ratio is high compared to other international studies owing to differences in the referral pattern.

Patients with Parkinson's disease develop motor symptoms gradually over the years with progressive degeneration of dopaminergic neurons. Clinical manifestations appear when more than 50\% dopaminergic neuronal loss has occurred. The mean duration of disease before seeking surgical intervention in our study was 9.03 years with varying range of 3 to 15 years. Similar results were seen in patients undergoing VIM Thalamotomy in Fraix et al. study (mean age of 8 years and range of 1-19 years) and patients undergoing Subthalamotomy in Alvarez et al study (mean age of 10.8 years and rage of $5-27$ years). ${ }^{10,11}$

Patients receive anti-Parkinsonian medications for a variable period of time before they develop motor fluctuations and dyskinesia with escalating doses. In our study, the mean duration of medical treatment before surgical intervention was 7.29 years with range of 2 to 15 years. Olanow et al. estimated that as many as $50 \%$ of Parkinsonian patients on levodopa for five years develop motor fluctuations and dyskinesia. ${ }^{12}$ Motor complications are more frequent in younger onset of the disease. In our study four patients presented with dyskinesia. 
Both, Stereotactic VIM Thalamotomy and Subthalamotomy were associated with significant improvement in post-operative UPDRS scores. In a study conducted by Sobstyl et al., among 41 tremor predominant PD patients who underwent VIM Thalamotomy, the mean preoperative UPDRS of 11.2 improved to $2.6^{7}$. Similar results were seen in Boecker et al. study following VIM Thalamotomy in tremor dominant Parkinsonian patients ${ }^{13}$. Following Subthalamotomy by Tarsy et al. in 89 Parkinsonian patients, UPDRS scores while off medication improved by $50 \%$ at 12 months. ${ }^{14}$ A study by patel et al. in 2003, showed that Stereotactic lesioning of STN in 21 Parkinsonian patients had significant improvement in rigidity, contralateral tremor and bradykinesia with maximum effect on tremor component. There was a significant improvement in the UPDRS scores on medication and off medication at 6, 12 and 24 months follow up ${ }^{15}$.In another study by Su et al. in 2002, STN lesioning in 12 patients with 12 months follow up showed improvement in UPDRS scores by $30 \%$ in off period, $38 \%$ in on period. ${ }^{16}$

In our study, improvement in mean post-operative UPDRS score was significantly higher in Subthalamotomy group compared to VIM Thalamotomy group. This difference in two groups was persistent throughout 3 weeks, 6 weeks and 3 months follow-up. This significant difference in two groups may be attributed to the fact that STN lesioning is associated with post-operative improvement in not only the tremor component but also rigidity, bradykinesia and postural instability. ${ }^{16}$ On the other hand VIM lesioning has no or minimal effect on rigidity, bradykinesia and rigidity. ${ }^{17}$

We also studied the tremor component of UPDRS score separately. The mean pre-operative tremor component score in STN group was 2.63. Nine patients $(47.36 \%)$ had complete cessation of tremor at 3 months follow up while ten patients had significant improvement with mean score of 0.53 at latest followup. Similarly, mean pre-operative tremor score in VIM group was 2.58. Eight patients $(42.1 \%)$ had complete cessation of tremor at 3 months follow-up while 11 patients had significant improvement with mean score of 0.58 at latest follow-up. Jankovic et al. in 1995 conducted a retrospective study among 42 patients who underwent Stereotactic VIM Thalamotomy for Parkinsonian tremor. During follow up $86 \%$ of patients had complete cessation or significant improvement in contralateral tremor. ${ }^{18}$ Similar results were shown by Balás et al. in 2001, where he conducted Thalamotomy in 34 tremor predominant Parkinsonian patients with 12 months average followup. The result showed $88 \%$ of patients with complete cessation or marked improvement in contralateral tremor. ${ }^{19}$ Alvarez et al. in 2009 studied the role of Subthalamotomy in 68 Parkinsonian patients which showed tremor score of 2.2 pre-operatively improved to 0.2 at 12 months follow-up. ${ }^{11}$

There was no significant difference in terms of improvement in tremor scores between two groups. No study is available in literature review comparing STN and VIM lesioning. However, Parihar et al. in 2015 compared the results of VIM and STN stimulation (DBS) in Parkinsonian tremor. The degree of improvement in postural or action tremor scores between VIM DBS and STN DBS was not significantly different. Postural/action tremor improved $72 \%$ in the VIM DBS group and $68 \%$ in the STN group. ${ }^{20}$

Post-operative complications were higher in stereotactic STN lesioning (21.05\%) compared to VIM lesioning $(10.52 \%)$. There was no mortality or cognitive impairment in both groups. Our results were comparable with other international studies. Jancovic et al. encountered immediate postoperative complications in $58 \%$ of patients following VIM lesioning with most common being contralateral weakness $(34 \%)$ followed by dysarthria $(29 \%)$ and confusion $(23 \%)$. But these complications rapidly resolved during post-operative period ${ }^{18}$. Similarly, in a study conducted by Sobstyl et al. in 41 tremor predominant Parkinsonian patients who underwent stereotactic VIM Thalamotomy, 13 patients had transient and 6 had permanent complications ${ }^{7}$. In a case series of 89 Subthalamotomy conducted by Alvarez et al., 52 patients developed contralateral dyskinesia that resolved gradually in 38 cases. However, 14 patients had hemiballism and chorea which required Pallidotomy ${ }^{11}$. Relatively higher incidence of complications in STN group may be due to a small target of Subthalamic nucleus. Thus, macroelectrode monitoring helps proper localization of the target and prevents possible complications.

Recently, MR-guided high intensity focused ultrasound lesioning of VIM and Subthalamic nucleus has been considered safe and effective in treatment of Parkinsonian patients with lower complications rate like dysphagia and dysarthria ${ }^{21}$. Similarly, using modern functional Stereotactic Radiosurgery (SRS) parameters, radiosurgery Thalamotomy has become a safe and useful procedure for patients who are not 
suitable for an open surgical procedure. The reported results and complications of SRS are comparable to those of thalamic lesions generated by radiofrequency procedures. However, further studies are necessary to establish the role of SRS targeting the STN, since its small size and complex anatomical relationships make this nucleus less suitable for the procedure. ${ }^{22}$

\section{CONCLUSION}

Both Stereotactic VIM Thalamotomy and Subthalamotomy are equally effective in relieving tremor in tremor predominant Parkinsonism. However, overall improvement in total UPDRS score is significantly higher following STN lesioning compared to VIM lesioning. And this improvement comes at a cost of higher complication rate compared to VIM Thalamotomy.

\section{REFERENCES}

1. Muangpaisan W, Mathews A, Hori H, Seidel D. A systematic review of the worldwide prevalence and incidence of Parkinson's disease. J Med Assoc Thai. 2011; 94 (6): 749-755.

2. Twelves D, Perkins KS, Counsell C. Systematic review of incidence studies of Parkinson's disease. Mov Disord. 2003; 18: 19-31.

3. Rodriguez-Oroz MC, Jahanshahi M, Krack P, Litvan I, Macias R, Bezard E, Obeso JA. Initial clinical manifestations of Parkinson's disease: features and pathophysiological mechanisms. Lancet Neurol. 2009; 8: 1128-1139.

4. Rodrigues e Silva AM, Geldsetzer F, Holdorff B, Kielhorn FW, Balzer-Geldsetzer M, Oertel WH, Hurtig $\mathrm{H}$, Dodel R. Who was the man who discovered the "Lewy bodies"? Mov Disord. 2010; 25: 1765-1773.

5. Wirdefeldt K, Adami HO, Cole P, Trichopolous D and Mandel J. Epidemiology and Etiology of Parkinson disease: a review of the evidence. Eur $\mathrm{J}$ Epidemio. 2011; 26 (1): 51-58.

6. Mazzucchi S., Frosini D., Bonuccelli U., Ceravolo R. Current treatment and future prospects of dopa-induced dyskinesias. Drugs Today (Barc). 2015; 51 (5): 315329.

7. Sobstyl M, Zabek M, Koziara H, Kadziołka B, Mossakowski Z. Unilateral thalamotomy for the treatment of tremor dominant Parkinson's disease. Neurol Neurochir Pol. 2006; 40 (2): 119-126.

8. Van Den Eeden SK, Tanner CM, Bernstein AL, Fross $\mathrm{RD}$, Leimpeter A, Bloch DA, Nelson LM. Incidence of Parkinson's disease: variation by age, gender, and race/ ethnicity. Am J Epidemiol. 2003; 157 (11): 1015-1022.

9. Lee A, Gilbert RM. Epidemiology of Parkinson
Disease. Neurol Clin. 2016; 34 (4): 955-965.

10. Fraix V, Pollak P, Moro E, Chabardes S, Xie J, Ardouin C, Benabid AL. Subthalamic nucleus stimulation in tremor dominant Parkinsonian patients with previous thalamic surgery. J Neurol Neurosurg Psychiatry, 2005; 76: 246-248.

11. Alvarez L, Macias R, Pavón N, López G, RodríguezOroz MC, Rodríguez R, Alvarez M, Pedroso I, Teijeiro J, Fernández R, Casabona E, Salazar S, Maragoto C, Carballo M, García I, Guridi J, Juncos JL, DeLong MR, Obeso JA. Therapeutic efficacy of unilateral Subthalamotomy in Parkinson's disease: results in 89 patients followed for up to 36 months. J Neurol Neurosurg Psychiatry, 2009; 80 (9): 979-985.

12. Olanow CW, Watts RL, Koller WC. An algorithm (decision tree) for the management of Parkinson's disease (2001): treatment guidelines. Neurology, 2001; 56: $\mathrm{S} 1$.

13. Boecker H, Wills AJ, Ceballos-Baumann A, Samuel M, Thomas DG, Marsden CD, Brooks DJ. Stereotactic thalamotomy in tremor-dominant Parkinson's disease: an H2 (15) O PET motor activation study. Ann Neurol. 1997; 41 (1): 108-111.

14. Tarsy D. Does subthalamotomy have a place in the treatment of Parkinson's disease? J Neurol Neurosurg Psychiatry, 2009; 80: 939.

15. Patel NK, Heywood P, O'Sullivan K, McCarter R, Love $\mathrm{S}$, Gill SS. Unilateral subthalamotomy in the treatment of Parkinson's disease. Brain, 2003; 126: 1136-1145.

16. Su PC, Tseng HM, Liu HM, Yen RF, Liou HH. Subthalamotomy for advanced Parkinson disease. J Neurosurg. 2002; 97: 598-606.

17. Chao Y, Gang L, Na ZL, Ming WY, Zhong WS, Mian WS. Surgical Management of Parkinson's disease: Update and Review. Interv Neuroradiol. 2007; 13 (4): 359-368.

18. Jankovic J, Cardoso F, Grossman RG, Hamilton WJ. Outcome after stereotactic thalamotomy for Parkinsonian, essential and other types of tremor. Neurosurgery, 1995; 37 (4): 680-687.

19. Balás I. et al. Stereotactic Thalamotomy for Parkinsonian and others types of tremor: Experiences of thalamic multiunit burst activity by means of semimicroelectrode. Rev Neurol. 2001; 32(16): 520-524.

20. Parihar R, Alterman R, Papavassiliou E, Tarsy D, Shih LC. Comparison of VIM and STN DBS for Parkinsonian Resting and Postural/Action Tremor. Tremor Other Hyperkinet Mov (N Y). 2015; 5: 321.

21. S. Hägele-Link, N.A. Wegener, S.R. Schreglmann, J. Rosenfeld, M. Mueller-Baumberger, R. Bauer, A. Lebeda, B. Werner, E. Martin, G. Kägi. Transcranial unilateral MR guided high intensity focused ultrasound in Parkinson's disease or essential tremor seems to be save concerning dysphagia and dysarthria. Mov Disord. 2016: 31 .

22. Frighetto L, Bizzi J, Annes RD, Silva Rdos S, Oppitz P. 


\section{Additional Information}

Disclosures: Authors report no conflict of interest.

Ethical Review Board Approval: The study was conformed to the ethical review board requirements.

Human Subjects: Consent was obtained by all patients/participants in this study.

Conflicts of Interest:

In compliance with the ICMJE uniform disclosure form, all authors declare the following:

Financial Relationships: All authors have declared that they have no financial relationships at present or within the previous three years with any organizations that might have an interest in the submitted work.

Other Relationships: All authors have declared that there are no other relationships or activities that could appear to have influenced the submitted work.

Address for Correspondence:

Somraj Lamichhane

Department of Neurosurgery, Lahore General Hospital, Lahore - Pakistan

Email: tandisom@gmail.com

\section{AUTHORS CONTRIBUTIONS}

\begin{tabular}{|l|l|l|}
\hline Sr.\# & Author's Full Name & Intellectual Contribution to Paper in Terms of: \\
\hline 1. & Somraj Lamichhane & Study design and methodology. \\
\hline 2. & Khalid Mahmood & Paper writing, referencing, data calculations and \\
\hline
\end{tabular}

Date of Submission: 31-07-2020

Date of Revision: 11-08-2020

Date of Online Publishing: 25-09-2020

Date of Print: 30-09-2020 